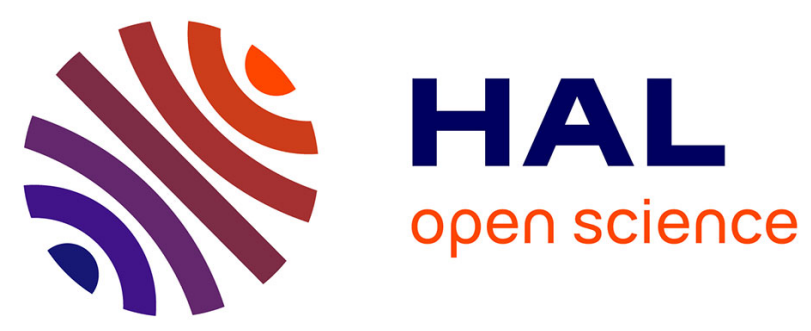

\title{
Patchy Supramolecular Bottle-Brushes Formed by Solution Self-Assembly of Bis(urea)s and Tris(urea)s Decorated by Two Incompatible Polymer Arms
}

Sylvain Catrouillet, Laurent Bouteiller, Olivier Boyron, Cédric Lorthioir, Erwan Nicol, Sandrine Pensec, Olivier Colombani

\section{To cite this version:}

Sylvain Catrouillet, Laurent Bouteiller, Olivier Boyron, Cédric Lorthioir, Erwan Nicol, et al.. Patchy Supramolecular Bottle-Brushes Formed by Solution Self-Assembly of Bis(urea)s and Tris(urea)s Decorated by Two Incompatible Polymer Arms. Langmuir, 2016, 32 (35), pp.8900-8908. 10.1021/acs.langmuir.6b01609 . hal-01696680

\section{HAL Id: hal-01696680 https://hal.science/hal-01696680}

Submitted on 27 Aug 2020

HAL is a multi-disciplinary open access archive for the deposit and dissemination of scientific research documents, whether they are published or not. The documents may come from teaching and research institutions in France or abroad, or from public or private research centers.
L'archive ouverte pluridisciplinaire HAL, est destinée au dépôt et à la diffusion de documents scientifiques de niveau recherche, publiés ou non, émanant des établissements d'enseignement et de recherche français ou étrangers, des laboratoires publics ou privés. 


\title{
Patchy Supramolecular Bottle-Brushes Formed by
}

\author{
Solution Self-Assembly of Bis(urea)s and
}

Tris(urea)s Decorated by Two Incompatible Polymer

\begin{abstract}
Arms
Sylvain Catrouillet ${ }^{a}$, Laurent Bouteiller ${ }^{b}$,Olivier Boyron ${ }^{c}$, Cédric Lorthioir ${ }^{d}$, Erwan Nicol, $^{a}$, Sandrine Pensec ${ }^{b}$ and Olivier Colombani ${ }^{a^{*}}$
\end{abstract}

`LUNAM Université, Université du Maine, IMMM - UMR CNRS 6283, Université du Maine, av. O. Messiaen, 72085 Le Mans cedex 9, France.

'Sorbonne Universités, UPMC Univ Paris 06, CNRS, Institut Parisien de Chimie Moléculaire, Equipe Chimie des Polymères, 4 Place Jussieu, F-75005 Paris, France

- Université de Lyon, Univ. Lyon 1, CPE Lyon, CNRS UMR 5265, Laboratoire de Chimie Catalyse Polymères et Procédés (C2P2), Bat 308F, 43 Bd du 11 Novembre 1918, 69100 Villeurbanne, France

`Université Paris Est, ICMPE (UMR7182), CNRS, UPEC, F-94320 Thiais, France

KEYWORDS. Self-assembly, urea, supramolecular, cylinders, nanotubes, Janus. 


\section{ABSTRACT.}

In an attempt to design urea-based Janus nanocylinders through a supramolecular approach, non symmetrical bis(urea)s and tris(urea)s decorated by two incompatible polymer arms, namely poly(styrene) (PS) and poly(isobutylene) (PIB), were synthesized using rather straightforward organic and polymer chemistry techniques. Light scattering experiments revealed that these molecules self-assembled in cyclohexane by cooperative hydrogen bonds. The extent of selfassembly was limited for the bis(urea)s. On the contrary, reasonably anisotropic 1D structures (small nanocylinders) could be obtained with the tris(urea)s $\left(\mathrm{N}_{\text {age }} \sim 50\right)$ which developed six cooperative hydrogen bonds per molecule. ' $\mathrm{H}$ transverse relaxation measurements and NOESY NMR experiments in cyclohexane revealed that perfect Janus nanocylinders with one face consisting of only PS and the other of PIB were not obtained. Nevertheless, phase segregation between the PS and PIB chains occurred to a large extent, resulting in patchy cylinders containing well separated domains of PIB and PS chains. Reasons for this behavior were proposed, paving the way to improve the proposed strategy toward true urea-based supramolecular Janus nanocylinders. 


\section{Introduction}

Janus particles were named after the roman god Janus because they possess two faces with different chemistries. ${ }^{1-2}$ Micron-sized Janus particles are the easiest to prepare and have found many applications in optics, catalysis or emulsion stabilization..$^{3.5}$ On the contrary, the elaboration of anisotropic Janus particles such as cylinders, particularly at the nanoscale, is extremely difficult. The first convincing method leading to polymeric Janus nanocylinders has been proposed by Müller et al. ${ }^{6.7}$ Their synthetic strategy consists in preparing ABC triblock copolymers by anionic polymerization; organizing them in bulk into a complex morphology where the A and $\mathrm{C}$ blocks form a lamellar phase and the B block forms cylinders between the lamellae; cross-linking the B block; and finally dispersing the Janus cylinders in solution by sonication. This technique leads to Janus nanocylinders which act as very efficient emulsion stabilizers ${ }^{8}$ or self-assemble into very long superstructures in a selective solvent for one of their faces.? However, this preparation method requires demanding synthetic efforts followed by a complex processing of the triblock copolymers into particles. Moreover, the length of the cylinders is determined by the sonication process and is not thermodynamically controlled.

An interesting alternative approach to construct complex structures is to rely on supramolecular chemistry where rather simple building blocks self-assemble through non covalent interactions into much more complex structures. ${ }^{9-12}$ In this context, we have shown very recently that bis(urea) $\mathbf{S}^{13}$ and tris(urea)s, ${ }^{1415}$ consisting of respectively two or three urea functions separated by rigid aromatic rings, could be decorated in a rather straightforward way by polymeric side-chains of different lengths and chemical structures. When these molecules are decorated on each side with the same type of polymer, they self-assemble in solution to form supramolecular structures for which the extent of aggregation results from a balance between the strength of the hydrogen bonding units 
and the steric hindrance caused by the polymeric side-chains. Typically, much longer and anisotropic supramolecular bottle-brushes are obtained with a tris(urea) than with a bis(urea) decorated by the same poly(isobutylene) (PIB) side-chains. ${ }^{14}$ Moreover, tris(urea)s decorated with two short poly(styrene) (PS) side-chains formed much smaller structures than those decorated by two PIB side-chains because of the bulkiness of the styrene units which partially hinders selfassembly..$^{16}$

Here, we investigated the possibility to prepare non-symmetrical bis(urea)s and tris(urea)s decorated by two polymer arms of different chemical natures in the prospect of forming supramolecular Janus bottle-brushes with these building blocks. PS and PIB were selected for this study because these polymers are incompatible, favouring phase segregation into a Janus architecture, and do not contain polar groups which may interfere with the formation of hydrogen bonds. A non-symmetrical bis(urea) $\left(\mathrm{S}_{42} \mathrm{U}_{2} \mathrm{IB}_{23}\right)$ and a non-symmetrical tris(urea) $\left(\mathrm{S}_{20} \mathrm{U}_{3} \mathrm{IB}_{39}\right)$ were thus synthesized (Figure 1). Their self-assembly in solution was studied by light scattering in cyclohexane and the Janus character of the assemblies was investigated by 2D 'H NOESY NMR experiments and ${ }^{1} \mathrm{H}$ transverse relaxation measurements.

It should be noted that Perrier et al. ${ }^{77}$ have recently reported the first example of Janus nanocylinders prepared directly in solution by self-assembly of cyclic-oligopeptides decorated with two incompatible polymer arms. The cyclic-oligopeptides stacked onto each other by strong cooperative hydrogen bonds, leading to supramolecular nanotubes, whereas the polymer arms phase-segregated and generated the Janus character of the cylinders as proven by NOESY NMR..$^{18 .}$ ${ }_{19}$ The synthesis of the cyclic oligopeptides however requires the use of solid-supported peptide synthesis, ${ }^{2021}$ limiting their utilization to specific applications with high added value. On the 
contrary, the synthesis of bis(urea)s and tris(urea)s is rather straightforward ${ }^{13-14,16}$ and could allow an easier design of Janus nanocylinders.
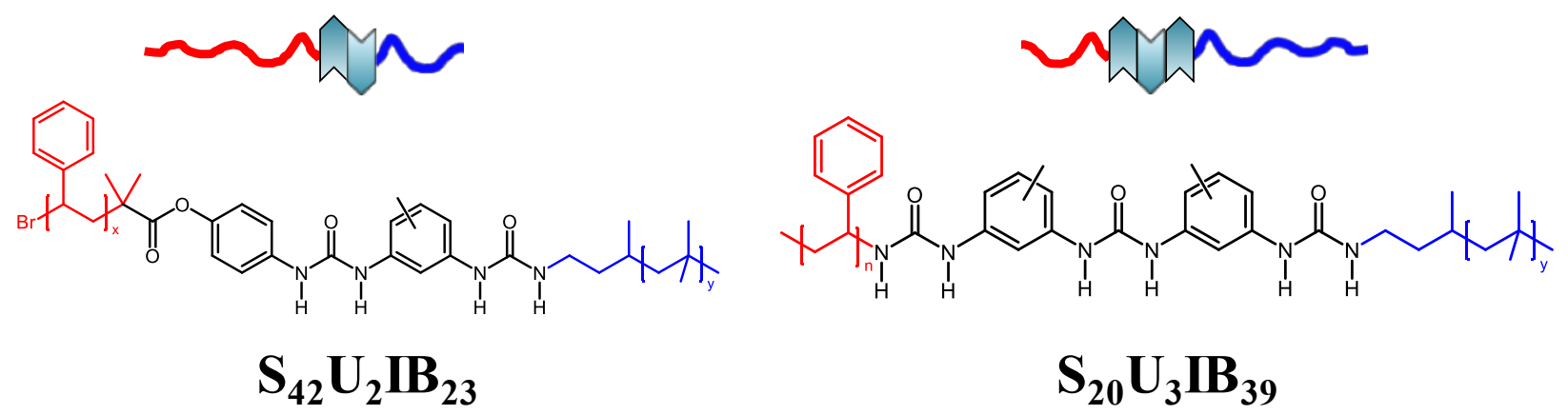

Figure 1. Schematic representation and chemical structures of $\mathrm{S}_{42} \mathrm{U}_{2} \mathrm{IB}_{23}$ and $\mathrm{S}_{20} \mathrm{U}_{3} \mathrm{IB}_{39}$ molecules. S stands for poly(styrene) and IB for poly(isobutylene), the subscripts correspond to the number average degrees of polymerization of each block. $\mathrm{U}_{2}$ corresponds to a bis(urea) self-assembling unit and $\mathrm{U}_{3}$ to a tris(urea).

\section{Materials and Methods}

\section{Synthesis of the non-symmetrical bis(urea) and tris(urea).}

The syntheses of the non-symmetrical bis(urea) $\mathrm{S}_{42} \mathrm{U}_{2} \mathrm{IB}_{23}$ and tris(urea) $\mathrm{S}_{20} \mathrm{U}_{3} \mathrm{IB}_{39}$ represented on Figure 1 was achieved using rather straightforward organic chemistry and controlled radical polymerization steps as detailed in the Supporting Information.

\section{Preparation of the solutions of $S_{42} U_{2} I B_{23}$ and $S_{20} U_{3} I B_{39}$.}

Stock polymer solutions in cyclohexane were prepared at $1,10,50$ or $100 \mathrm{~g} / \mathrm{L}$ by direct dissolution of the polymer. The polymers dissolved spontaneously at room temperature and stable solutions were obtained after 2-24 $\mathrm{h}$ depending on the concentration and type of polymer. Unfiltered solutions contained a very small weight fraction of very large aggregates that were removed by filtration through $0.2 \mu \mathrm{m}$ pore size Acrodisc filters. Dilutions were made by adding 
filtered solvent (filter pore diameter $=0.02 \mu \mathrm{m}$ ) and stirring for a few minutes at room temperature. In the case of $\mathrm{S}_{42} \mathrm{U}_{2} \mathrm{IB}_{23}$, the solutions thus prepared could be characterized directly and remained stable for weeks after their preparation. Solutions directly prepared at $10 \mathrm{~g} / \mathrm{L}$ gave the same results as solutions diluted to $10 \mathrm{~g} / \mathrm{L}$ from a stock solution at $50 \mathrm{~g} / \mathrm{L}$ proving that a reproducible stationary state was reached. For $\mathrm{S}_{20} \mathrm{U}_{3} \mathrm{IB}_{39}$, steady-state was reached within 3 days at room temperature.

Light scattering. Static and dynamic light scattering measurements were done using an ALVCGS3 system (ALV-Langen) operating with a vertically polarized laser with wavelength $\lambda=632.8$ $\mathrm{nm}$. The measurements were done at $20^{\circ} \mathrm{C}$ unless specified differently over a range of scattering wave vectors, $\mathrm{q}$, varying from $4.8 \times 10^{\circ} \mathrm{m}^{-1}$ to $2.8 \times 10^{7} \mathrm{~m}^{-1}(\mathrm{q}=4 \pi \mathrm{n} / \lambda \cdot \sin (\theta / 2)$, with $\theta$ the angle of observation and $\mathrm{n}$ the refractive index of the solvent). The apparent hydrodynamic radius was determined by dynamic light scattering and the apparent radius of gyration and molecular weight were determined by static light scattering as previously described.$^{16}$ The apparent radius of gyration $\left(R_{s}\right)$ was too small to be determined accurately for aggregates formed by $\mathrm{S}_{42} \mathrm{U}_{2} \mathrm{IB}_{23}\left(\mathrm{R}_{\mathrm{g}}<20 \mathrm{~nm}\right)$, but could be determined for $\mathrm{S}_{20} \mathrm{U}_{3} \mathrm{IB}_{39}$ as q. $\mathrm{R}_{\mathrm{s}}<1$.

Differential Refractometry. Measurements were done with an OptiLab rEX from Wyatt Technology Corporation $\left(\lambda_{0}=632 \mathrm{~nm}\right)$. The refractive index increment was measured in cyclohexane using 5 concentrations of $\mathrm{S}_{42} \mathrm{U}_{2} \mathrm{IB}_{23}$ or $\mathrm{S}_{20} \mathrm{U}_{3} \mathrm{IB}_{39}$ ranging from 1 to $5 \mathrm{~g} / \mathrm{L}$. In cyclohexane, $\partial \mathrm{n} / \partial \mathrm{C}=0.14 \mathrm{~mL} . \mathrm{g}^{-1}$ for $\mathrm{S}_{42} \mathrm{U}_{2} \mathrm{IB}_{23}$ and $\partial \mathrm{n} / \partial \mathrm{C}=0.13 \mathrm{~mL} \cdot \mathrm{g}^{-1}$ for $\mathrm{S}_{20} \mathrm{U}_{3} \mathrm{IB}_{39}$. These values are intermediate between the values found in the literature for pure PIB $\left(\partial \mathrm{n} / \partial \mathrm{C}=0.10 \mathrm{~mL} \cdot \mathrm{g}^{-1}\right)$ and pure PS $\left(\partial \mathrm{n} / \partial \mathrm{C}=0.18 \mathrm{~mL} \cdot \mathrm{g}^{-1}\right)$ in this solvent as expected.$^{22}$

\section{Solution-state NMR.}

a) $1 D{ }^{1} \mathrm{H}$ transverse relaxation experiments. ${ }^{1} \mathrm{H}$ NMR relaxation experiments were performed on a Bruker Avance 300 NMR spectrometer operating under a static magnetic field of 
7.0 T $\left({ }^{1} \mathrm{H}\right.$ Larmor frequency of $\left.300.1 \mathrm{MHz}\right)$, with a $10 \mathrm{~mm} \mathrm{X/1} \mathrm{H}$ probe. The ${ }^{1} \mathrm{H}$ transverse

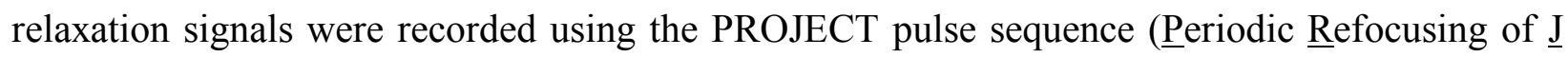
Evolution by $\underline{\text { Coherence }}$ Transfer $)^{23}$ which allows the effects of ${ }^{1} \mathrm{H}$ chemical shift dispersion, magnetic field inhomogeneities and diffusion to be refocused (partly, for diffusion), in a similar manner as in the Carr-Purcell-Meiboom-Gill (CPMG) experiment. ${ }^{24-25}$ The advantage of PROJECT stands in its additional ability to remove the modulation of the spin echoes by the ${ }^{1} \mathrm{H}$ homonuclear scalar couplings. The ${ }^{1} \mathrm{H} 90^{\circ}$ pulse length was set to $16 \mu \mathrm{s}$, the inter-pulse delay $\tau$ to $0.125 \mathrm{~ms}$ and the recycle delay to $5 \mathrm{~s}$. The ${ }^{1} \mathrm{H}$ transverse relaxation signals, $M(t)$, were systematically normalized by $M_{0}$, the ${ }^{1} \mathrm{H}$ magnetization of the considered protons recorded with a single cycle $\left[\tau-180^{\circ}-\tau-90^{\circ}-\tau-180^{\circ}-\tau\right]$ of the PROJECT experiment. All these relaxation measurements were carried out at a sample concentration of 12 g.L.- $\mathrm{L}^{-1}$ and a regulated temperature of $25^{\circ} \mathrm{C}$.

b) $2 D^{1} H$ NOESY. The $2 \mathrm{D}{ }^{1} \mathrm{H}$ NOESY experiments were carried out on a Bruker Avance II $400 \mathrm{MHz}$ NMR spectrometer, coupled to a magnetic field of $9.4 \mathrm{~T}\left({ }^{1} \mathrm{H}\right.$ Larmor frequency of

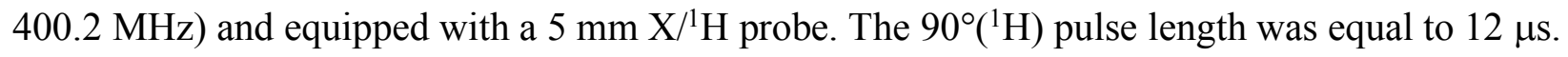
Measurements were performed with various values of the mixing time $t_{\mathrm{m}}$, ranging from $10 \mathrm{~ms}$ to $800 \mathrm{~ms}$. The recycle delay, adjusted according to the $T_{1}\left({ }^{1} \mathrm{H}\right)$ relaxation behavior, was set to $4 \mathrm{~s}$. Phase-sensitive two-dimensional time domains were recorded and processed following the StatesTPPI mode. 2048 slices were acquired in the $t_{1}$ dimension and the number of scans per $t_{1}$ slice stood between 8 and 24. For these experiments, the temperature was set to $25^{\circ} \mathrm{C}$.

\section{Results and discussion}

\section{Self-Assembly in Cyclohexane.}


Choice of the temperature. The self-assembly of $\mathrm{S}_{42} \mathrm{U}_{2} \mathrm{IB}_{23}$ and $\mathrm{S}_{20} \mathrm{U}_{3} \mathrm{IB}_{39}$ in cyclohexane was studied at $20^{\circ} \mathrm{C}$ by static and dynamic light scattering. Cyclohexane is a good solvent for PIB, but the solvent quality for PS decreases with decreasing temperature. ${ }^{26}$ Although the self-assembly and solubility in cyclohexane of tris(urea)s functionalized with two PS chains was shown to be affected by temperature; ${ }^{; 6}$ the bottle-brush topology of the self-assembled PS structures granted them a higher solubility than that of linear PS of same molecular weight. Here, it was checked that $\mathrm{S}_{42} \mathrm{U}_{2} \mathrm{IB}_{23}$ and $\mathrm{S}_{20} \mathrm{U}_{3} \mathrm{IB}_{39}$ remained macroscopically soluble down to $12{ }^{\circ} \mathrm{C}$ at least and that their selfassembly was not different at 12 and $20^{\circ} \mathrm{C}$ (data not shown) so that the results described at $20^{\circ} \mathrm{C}$ correspond to good solvent conditions for these polymers.

Non-symmetrical bis(urea) $\mathrm{S}_{42} \mathrm{U}_{2} \mathrm{IB}_{23}$. The self-assembly of $\mathrm{S}_{42} \mathrm{U}_{2} \mathrm{IB}_{33}$ in cyclohexane was studied between 1 and $50 \mathrm{~g} / \mathrm{L}$. The scattered intensity was too low for accurate measurements below $1 \mathrm{~g} / \mathrm{L}$. Only one diffusive mode of relaxation was observed by dynamic light scattering (DLS) down to 1 $\mathrm{g} / \mathrm{L}$. Figure 2 shows the concentration dependence of the apparent aggregation number (apparent $\mathrm{N}_{\mathrm{ag}}$ ) calculated from the apparent molecular weight $\mathrm{M}_{a}$ of the scatterers using the weight average

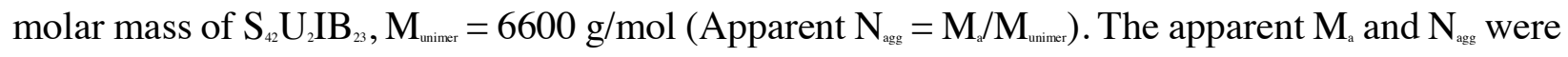
almost constant between 1 and $50 \mathrm{~g} / \mathrm{L}$ in agreement with previous findings on bis(urea)s and tris(urea)s decorated by two identical polymer arms. ${ }^{1.16} \mathbf{M}_{s}$ therefore corresponded to $\mathbf{M}_{w}$, the true molecular weight of the aggregates which was equal to $74000 \mathrm{~g} / \mathrm{mol}$, giving $\mathrm{N}_{\mathrm{agg}} \sim 10$. The hydrodynamic radius determined by DLS was also constant within experimental error between 1 and $50 \mathrm{~g} / \mathrm{L}, \mathrm{R}_{\mathrm{n}}=6 \mathrm{~nm}$. For all concentrations investigated, the scattered intensity did not depend on the scattering wave vector, indicating that the aggregates were small $\left(\mathrm{R}_{\mathrm{s}}<20 \mathrm{~nm}\right)$. Considering that the distance between two urea groups is $0.46 \mathrm{~nm},{ }^{27}$ the total length of the supramolecular backbone of the aggregates was close to $5 \mathrm{~nm}$, which was short compared to their hydrodynamic 
diameter $\left(D_{\mathrm{h}} \sim 12 \mathrm{~nm}\right)$ or to the hydrodynamic diameter of the unassembled polymer $\left(D_{\mathrm{h}} \sim 4 \mathrm{~nm}\right.$, measured by adding $2 \mathrm{wt} \%$ of ethanol in cyclohexane to disrupt all hydrogen bonds). This implied that the aggregates were star-shaped rather than anisotropic. A relatively small aggregation number $\left(\mathrm{N}_{\text {agg }} \sim 10\right)$ was also observed for a bis(urea) functionalized with two PIB chains, $\operatorname{IB}_{27} \mathrm{U}_{2} \mathrm{IB}_{27}$ (this molecule was called U2PIB2 in a former paper $^{14}$, , the arms of which had a similar length as those of $\mathrm{S}_{42} \mathrm{U}_{2} \mathrm{IB}_{23}$. This was explained by the fact that the hydrogen bonds formed between bis(urea)s are not strong enough to compensate the entropic penalty due to the stretching of the polymer arms in a bottle-brush structure. Taking into account on top of that the presence of a PS arm on one side which is also known to decrease the extent of self-assembly, ${ }_{16}^{16}$ it was not surprising that $\mathrm{S}_{42} \mathrm{U}_{2} \mathrm{IB}_{23}$ formed short structures. 


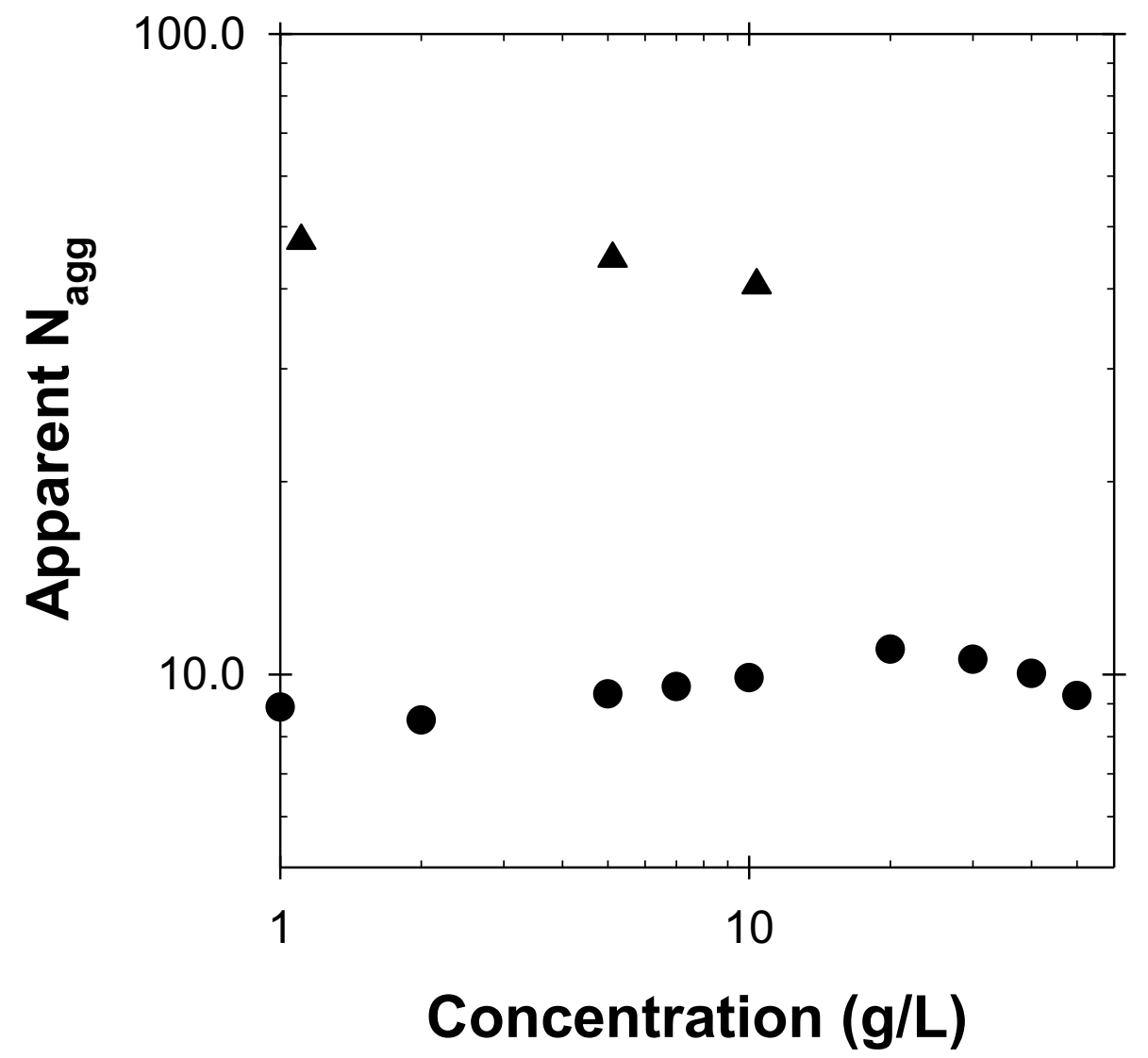

Figure 2. Evolution of the weight average apparent aggregation number with the concentration for (一) $\mathrm{S}_{{ }_{21}} \mathrm{U}_{2} \mathrm{IB}_{23}$ and ( $\left.\boldsymbol{\Delta}\right) \mathrm{S}_{20} \mathrm{U}_{3} \mathrm{IB}_{39}$ determined by static light scattering in cyclohexane.

Non-symmetrical tris(urea) $\mathrm{S}_{20} \mathrm{U}_{3} \mathrm{IB}_{39}$. The self assembly of the non-symmetrical tris(urea) $\mathrm{S}_{20} \mathrm{U}_{3} \mathrm{IB}_{39}$ was also studied in cyclohexane at $20^{\circ} \mathrm{C}$ by static and dynamic light scattering. The apparent molecular weight $\mathrm{M}_{2}$ was measured at three different concentrations: 1,5 and $10 \mathrm{~g} / \mathrm{L}$ and the corresponding apparent aggregation number (apparent $\mathrm{N}_{\mathrm{ag}}$ ) could be deduced using $\mathrm{M}_{\mathrm{unimer}}=$ $4900 \mathrm{~g} / \mathrm{mol}$ for $\mathrm{S}_{20} \mathrm{U}_{3} \mathrm{IB}_{39}$ (Figure 2). In this concentration range, $\mathrm{M}_{\mathrm{a}}$ did not depend significantly on the concentration and represented the weight average molar mass of the aggregates: $\mathrm{M}_{w}=$ $2.4 \times 10^{5} \mathrm{~g} / \mathrm{mol}$, corresponding to $\mathrm{N}_{\mathrm{ag}} \sim 50$. The aggregation number of the non-symmetrical 
tris(urea) was larger than that of the non-symmetrical bis(urea) as expected from previous results on symmetrical molecules decorated by PIB side-chains. ${ }^{14}$ Contrary to what was observed for $\mathrm{S}_{42} \mathrm{U}_{2} \mathrm{IB}_{2}$, the scattered intensity of $\mathrm{S}_{20} \mathrm{U}_{3} \mathrm{IB}_{39}$ solutions depended significantly on the scattering wave vector, from which a radius of gyration $\mathrm{R}_{s}=30 \mathrm{~nm}$ independent of the polymer concentration could be deduced. The hydrodynamic radius measured by DLS was $R_{n}=11 \mathrm{~nm}$. The ratio $R_{\varepsilon} / R_{n}$ was much higher than 1 , consistent with an elongated structure. Moreover, it was already proven by Small Angle Neutron Scattering (SANS) that tris(urea) decorated by two PS arms with a similar $\mathrm{DP}_{n}$ exhibited the characteristic $\mathrm{q}^{-1}$ dependency of the scattered intensity expected for rod-like structures. ${ }^{16}$ Considering a spacing of $0.46 \mathrm{~nm}$ between each hydrogen bonding tris(urea), the backbone formed by $\mathrm{S}_{20} \mathrm{U}_{3} \mathrm{IB}_{39}$ was calculated to be $22 \mathrm{~nm}$ long (length $=\left(\mathrm{N}_{\mathrm{ags}}-1\right) \times 0.46 \sim 22 \mathrm{~nm}$ ), which was much larger than the hydrodynamic diameter of the unassembled unimer $\left(D_{\mathrm{n}} \sim 4 \mathrm{~nm}\right)$. Overall, the structures formed by the non-symmetrical tris(urea) could be considered as short supramolecular bottle-brushes.

We have shown elsewhere that symmetrical tris(urea)s functionalized with PIB chains of approximately the same length formed much longer bottle brushes (persistence length $>300 \mathrm{~nm}$, $\left.\mathrm{N}_{\mathrm{egz}}>600\right)^{14}$ than those functionalized with PS chains because of the high steric hindrance of the bulky styrene units. ${ }^{16}$ Moreover, a small modification of the degree of polymerization of the PS chains drastically affected the aggregation number of the latter molecules. Quantitatively, $\mathrm{N}_{\mathrm{ag}}$ was respectively $\sim 100$ and $\sim 5$ for side chains having a degree of polymerization of $14\left(\mathrm{~S}_{14} \mathrm{U}_{3} \mathrm{~S}_{14}\right)$ or 34 $\left(S_{34} U_{3} S_{34}\right)$. Direct comparison of the symmetrical and non-symmetrical molecules is not possible because of the small differences of degrees of polymerization of the arms, but the aggregation number of the non-symmetrical $\mathrm{S}_{20} \mathrm{U}_{3} \mathrm{IB}_{39}$ is clearly closer to that of $\mathrm{S}_{34} \mathrm{U}_{3} \mathrm{~S}_{34}$ or $\mathrm{S}_{14} \mathrm{U}_{3} \mathrm{~S}_{14}$ than to that of $\mathrm{IB}_{27} \mathrm{U}_{3} \mathrm{IB}_{27}$ and is probably therefore limited by the presence of the bulky styrene chains. 


\section{Investigation of the Janus Character in solution}

Before assessing the Janus character of $\mathrm{S}_{42} \mathrm{U}_{2} \mathrm{IB}_{23}$ and $\mathrm{S}_{20} \mathrm{U}_{3} \mathrm{IB}_{39}$ particles in solution, the incompatibility of the PS and PIB arms was evaluated in the bulk. Considering PS volume fractions $\phi_{\mathrm{ps}}=0.72$ and $\phi_{\mathrm{ps}}=0.44$ respectively for $\mathrm{S}_{42} \mathrm{U}_{2} \mathrm{IB}_{23}$ and $\mathrm{S}_{20} \mathrm{U}_{3} \mathrm{IB}_{39}$, the Flory-Huggins interaction parameter $(\chi)$ of PS and PIB was $\chi \approx 0.55$ and $\chi \approx 0.47 .{ }^{28}$ The corresponding values of $\chi . \mathrm{N}$ were much higher than $2(\chi . \mathrm{N} \sim 15$ in both cases, with $\mathrm{N}$ the number of monomer units on both blocks) implying that the PS and PIB chains should remain effectively segregated in the bulk..$^{29}$ This was confirmed by DSC of $\mathrm{S}_{20} \mathrm{U}_{3} \mathrm{IB}_{39}$ which clearly revealed two glass transition temperatures corresponding respectively to the short PIB $\left(\mathrm{T}_{\mathrm{g}} \sim-65^{\circ} \mathrm{C}\right)$ and short $\mathrm{PS}\left(\mathrm{T}_{\mathrm{s}} \sim+75^{\circ} \mathrm{C}\right)$ arms.

The Janus character of the supramolecular aggregates was then studied directly in cyclohexane by ${ }^{1} \mathrm{H}$ transverse relaxation measurements and $2 \mathrm{D}{ }^{1} \mathrm{H}$ NOESY experiments. $2 \mathrm{D}{ }^{~} \mathrm{H}$ NOESY NMR experiments have already been used successfully to determine whether various assemblies display or not a Janus character..${ }^{1730.33}$ In contrast, ${ }^{1} \mathrm{H}$ transverse relaxation measurements in solution have been used in order to monitor the segmental mobility in various systems, among which bottle brushes, ${ }^{34}$ micelles ${ }^{35}$ or polymer mixtures, ${ }^{36}$ but never to probe the Janus character of supramolecular self-assemblies.

\subsection{Segmental dynamics of the PS and PIB arms.}

${ }^{1} \mathrm{H}$ transverse relaxation measurement is a highly sensitive method and interestingly, the corresponding relaxation decay is governed by several dynamical processes such as localized motions $\left(\mathrm{CH}_{3}\right.$ rotation for PIB, phenyl ring motions for PS), librations / conformational changes and also, on a longer time scale, segmental motions. ${ }^{37}$ The general idea of the technique is that the 
segmental motions of polymer repeating units are mostly influenced by the local friction they experience and therefore by their local environment. Therefore, if the non-symmetrical urea-based molecules studied here lead to Janus structures in cyclohexane, each type of arms should be surrounded only by arms of the same chemical nature and its ${ }^{1} \mathrm{H} T_{2}$ relaxation signal should be identical to that measured for symmetrical molecules decorated on both sides by the same type of arms with a similar molecular weight. On the contrary, a non Janus architecture would imply that PS and PIB arms are in close proximity, leading to an increase of the mobility of the styrene units in contact with isobutylene ones, whereas the mobility of the isobutylene units should concomitantly decrease. The segmental mobility of the styrene and IB units in the non-symmetrical molecules was therefore compared to that of the same units in reference symmetrical structures.

Reference symmetrical systems. The segmental mobility of the PS arms was measured for two reference tris(urea)s, $\mathrm{S}_{14} \mathrm{U}_{3} \mathrm{~S}_{14}$ and $\mathrm{S}_{34} \mathrm{U}_{3} \mathrm{~S}_{34}$ differing only by the number-average degree of polymerization of the PS side-chains (resp. 14 or 34). For PIB reference systems, a bis(urea), $\mathrm{IB}_{27} \mathrm{U}_{2} \mathrm{IB}_{27}$, and a tris(urea), $\mathrm{IB}_{27} \mathrm{U}_{3} \mathrm{IB}_{27}$, both having PIB side-chains with $27 \mathrm{IB}$ units were used. Details of the investigation of these references are given in section 2.1 of the Supporting Information.

Briefly, the ${ }^{1} \mathrm{H}$ transverse relaxation signal, $M(t)$, of the ortho aromatic protons and of the backbone $\mathrm{CH}$ in the PS arms could not be described by a monoexponential relaxation function as would be the case for a non-functional homopolymer. Instead, the data could be fitted by a sum of two exponential components: $M(t)=A_{\mathrm{s}} \times \exp \left[-t / T_{2, \mathrm{~s}}\right]+A_{1} \times \exp \left[-t / T_{2,1}\right]$ with $\mathrm{A}_{\mathrm{s}}$ and $\mathrm{A}_{1}$ the proportion of monomer units corresponding to each population and $\mathrm{T}_{2, \mathrm{~s}}$ and $\mathrm{T}_{2, \mathrm{l}}$ their respective $T_{2}$ relaxation times. The same behavior was observed for the ${ }^{1} \mathrm{H}$ transverse relaxation signal of the $\mathrm{CH}_{3}$ and the $\mathrm{CH}_{2}$ of the backbone for the PIB arms although the difference between $T_{2, \mathrm{~s}}$ and $T_{2,1}$ was less 
pronounced. The biexponential behavior observed for both symmetrical systems could be attributed to the anchoring of the polymer arms to the bis/tris(urea) self-assembling units which caused a significant gradient of segmental mobility: the units closer to the urea-based core were less mobile and therefore exhibited faster $T_{2}\left({ }^{1} \mathrm{H}\right)$ relaxation $\left(T_{2, \mathrm{~s}}\right)$ compared to those far from the urea-based core $\left(T_{2,1}\right)$. Importantly, this gradient of mobility was not influenced by the extent of self-assembly as the ${ }^{1} \mathrm{H}$ transverse relaxation signal was the same for the protons of the PIB arms in $\mathrm{IB}_{27} \mathrm{U}_{2} \mathrm{IB}_{27}$ and $\mathrm{IB}_{27} \mathrm{U}_{3} \mathrm{IB}_{27}$ although their aggregation number differed by more than one decade. Moreover, the number of monomer units the mobility of which was affected by the anchorage to the bis(urea)/tris(urea) did not vary significantly with the degree of polymerization or chemical structure of the arms and was about 10-15 units in all cases.

Non-symmetrical $S_{42} U_{2} I B_{23}$ bis(urea) and $S_{20} U_{3} I B_{39}$ tris(urea). Figure 3a compares the ${ }^{1} \mathrm{H}$ transverse relaxation signal obtained on the $\mathrm{CH}_{3}$ protons related to the $\mathrm{PIB}$ chains of the nonsymmetrical $\mathrm{S}_{42} \mathrm{U}_{21} \mathrm{IB}_{23}$ bis(urea) with that determined for the symmetrical $\mathrm{IB}_{27} \mathrm{U}_{2} \mathrm{IB}_{27}$, which is characterized by a similar number of PIB repeating units per arm. The $M(t)$ function determined for $\mathrm{S}_{42} \mathrm{U}_{2} \mathrm{IB}_{23}$ was found to superimpose with the one recorded on $\mathrm{IB}_{21} \mathrm{U}_{2} \mathrm{IB}_{2}$, clearly indicating that the PIB segmental dynamics was unchanged between $\mathrm{S}_{42} \mathrm{U}_{2} \mathrm{IB}_{23}$ and $\mathrm{IB}_{27} \mathrm{U}_{2} \mathrm{IB}_{27}$ despite the presence of two types of chains in $\mathrm{S}_{42} \mathrm{U}_{2} \mathrm{IB}_{23}$. In other words, these NMR relaxation experiments suggested that the PIB arms of $\mathrm{S}_{42} \mathrm{U}_{2} \mathrm{IB}_{23}$ were mostly surrounded by other PIB chains. This conclusion was further confirmed by the analysis of the transverse relaxation of the $\mathrm{CH}_{2}$ protons of the PIB mainchain, see section 2.1 of the Supporting Information. 
(a)

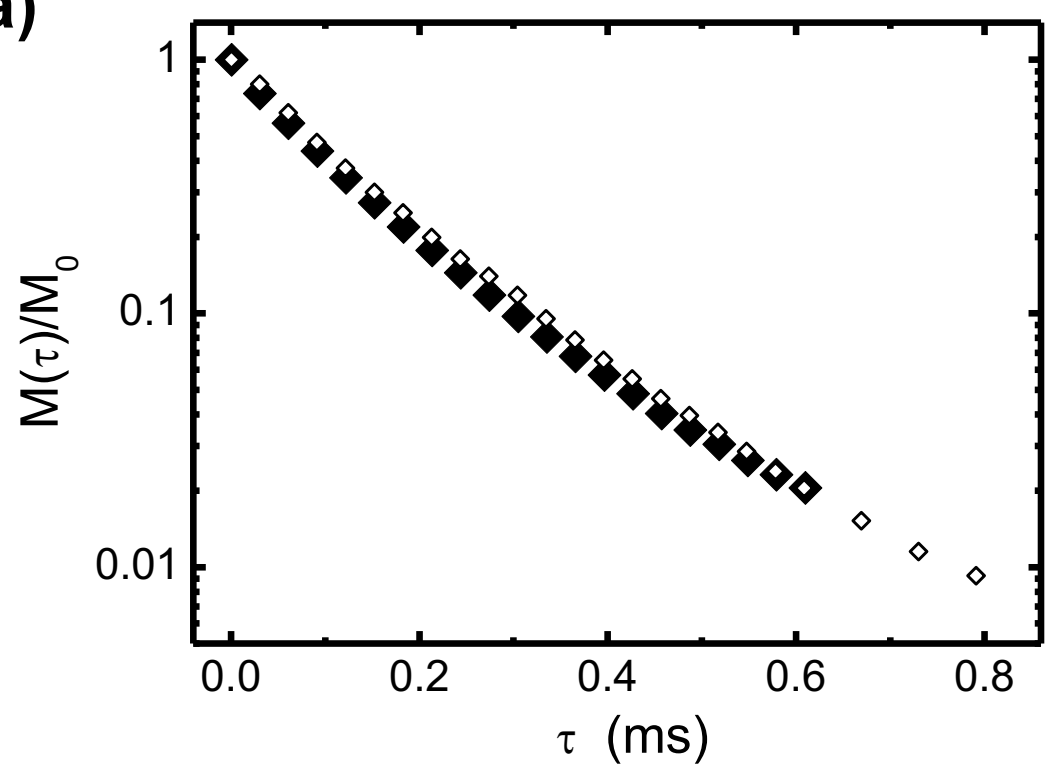

(b)

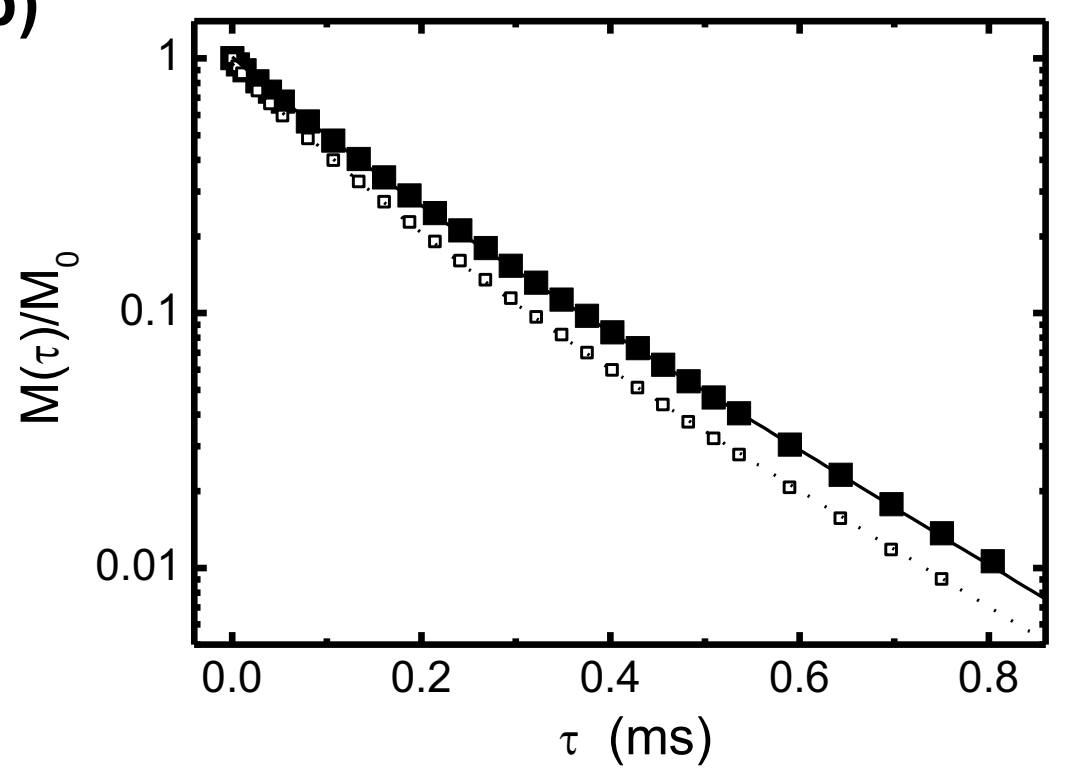

Figure 3. ' $\mathrm{H}$ transverse relaxation signal $M(t)$ of the $\mathrm{PIB}^{\mathrm{CH}} \mathrm{H}_{3}$ protons for a deuterated cyclohexane solution of: (a) $\mathrm{S}_{42} \mathrm{U}_{2} \mathrm{IB}_{23}(\diamond)$ and $\operatorname{IB}_{27} \mathrm{U}_{2} \mathrm{IB}_{27}(\diamond)$, this latter being used as a reference system and (b) $\mathrm{S}_{20} \mathrm{U}_{3} \mathrm{IB}_{39}(\mathbf{\square})$ and $\mathrm{IB}_{27} \mathrm{U}_{3} \mathrm{IB}_{27}(\square)$. The dotted line stands for the fit of $M(t)$, obtained for $\mathrm{IB}_{27} \mathrm{U}_{3} \mathrm{IB}_{27}$, whereas the solid line corresponds to the prediction of the $T_{2}$ relaxation signal for $\mathrm{S}_{20} \mathrm{U}_{3} \mathrm{IB}_{39}$, based on the fit derived for $\mathrm{IB}_{27} \mathrm{U}_{2} \mathrm{IB}_{27}$, taking into account the difference of the degree of polymerization 
of the PIB arms in both systems (see section 2.2.2 in the Supporting Information for details). All the data were recorded at $25^{\circ} \mathrm{C}$, with polymer concentrations of $12 \mathrm{~g} . \mathrm{L}^{-1}$.

At first glance, the $T_{2}$ relaxation signal of the PIB methyl protons looked different for the nonsymmetrical tris(urea), $\mathrm{S}_{20} \mathrm{U}_{3} \mathrm{IB}_{39}$, and the symmetrical reference $\mathrm{IB}_{27} \mathrm{U}_{3} \mathrm{IB}_{27}$, see Figure $3 \mathrm{~b}$. However, the long relaxation component of $M(t)$ displayed a similar relaxation time $T_{2}\left({ }^{1} \mathrm{H}\right)$ for both architectures, indicating that the PIB repeating units located far enough from the tris(urea) moieties had a similar extent of segmental reorientations. The difference observed between the ${ }^{1} \mathrm{H}$ transverse relaxation signals of the methyl protons of PIB in $\mathrm{S}_{20} \mathrm{U}_{3} \mathrm{IB}_{39}$ and in $\mathrm{IB}_{27} \mathrm{U}_{3} \mathrm{IB}_{27}$ was actually solely due to the fact that the PIB arms were longer for the former molecule. Indeed, assuming that the number of IB units slowed down by the central tris(urea) core was the same for the PIB arms of $\mathrm{IB}_{27} \mathrm{U}_{3} \mathrm{IB}_{27}$ and $\mathrm{S}_{20} \mathrm{U}_{3} \mathrm{IB}_{39}$, the corresponding molar fraction of slowed down units, $A_{s}$, could be calculated for $\mathrm{S}_{20} \mathrm{U}_{3} \mathrm{IB}_{39}$ on the basis of the value derived from $\mathrm{IB}_{27} \mathrm{U}_{3} \mathrm{IB}_{27}$. Then, the ${ }^{1} \mathrm{H}$ transverse relaxation signal expected for the $\mathrm{PIB} \mathrm{CH}$ protons of $\mathrm{S}_{20} \mathrm{U}_{3} \mathrm{IB}_{39}$ could be calculated as $M(t)=A_{s} \times \exp \left[-t / T_{2, s}\right]+A_{l} \times \exp \left[-t / T_{2, l}\right]$ where the values of $T_{2, s}$ and $T_{2,1}$ were the same as for the reference $\mathrm{IB}_{27} \mathrm{U}_{3} \mathrm{IB}_{27}$ (see details in section 2.2.2 of the Supporting Information and the calculated function $M(t)$ plotted in Figure $3 \mathrm{~b}$ ). An excellent agreement was observed between the predicted $M(t)$ and the experimental data, as shown in Figure 3b. As a consequence, as for $\mathrm{S}_{42} \mathrm{U}_{2} \mathrm{IB}_{23}$, it could be concluded that in $\mathrm{S}_{20} \mathrm{U}_{3} \mathrm{IB}_{39}$ the PIB arms were also mostly surrounded by other PIB arms.

In order to investigate the dynamical behavior of the PS arms within $\mathrm{S}_{42} \mathrm{U}_{2} \mathrm{IB}_{23}$ and $\mathrm{S}_{20} \mathrm{U}_{3} \mathrm{IB}_{39}$, we next focused our analysis on the ${ }^{1} \mathrm{H} T_{2}$ relaxation data derived from the area of the peak related 
to the PS aromatic protons (ortho position), see section 2.2.3 of the Supporting Information for details about the choice and treatment of this signal. 

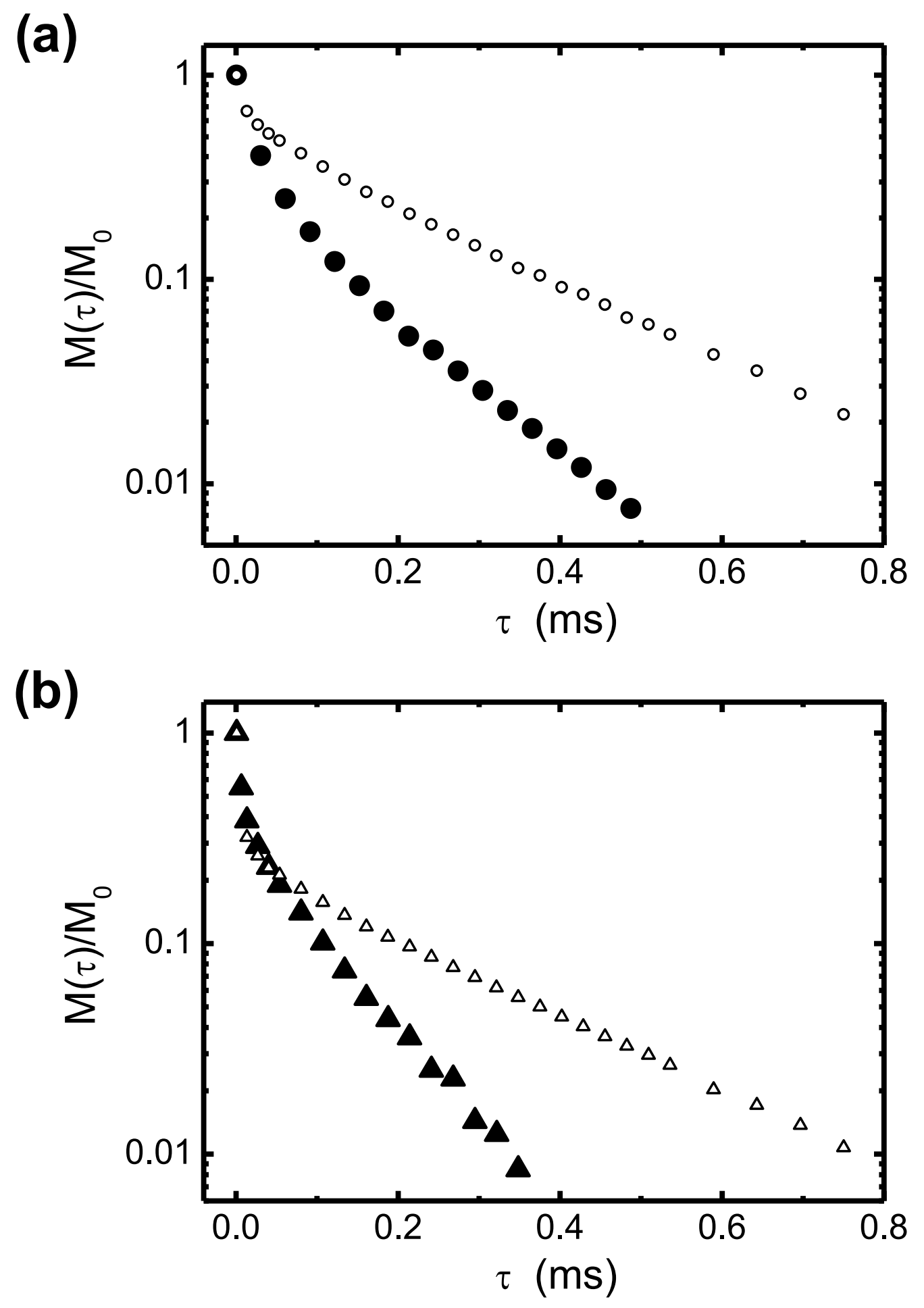

Figure 4. (a) ' $\mathrm{H}$ transverse relaxation behavior $M(t)$ for the $\mathrm{CH}$ protons of the PS phenyl groups (ortho position) obtained on: (a) $\mathrm{S}_{42} \mathrm{U}_{2} \mathrm{IB}_{23}(\mathbf{O})$ and $\mathrm{S}_{34} \mathrm{U}_{3} \mathrm{~S}_{34}(\bigcirc)$, used for comparison and (b) 
$\mathrm{S}_{20} \mathrm{U}_{3} \mathrm{IB}_{39}(\Delta)$ and $\mathrm{S}_{14} \mathrm{U}_{3} \mathrm{~S}_{14}(\triangle)$. All data were recorded at $25{ }^{\circ} \mathrm{C}$ in deuterated cyclohexane and at a polymer concentration of $12 \mathrm{~g} \cdot \mathrm{L}^{-1}$.

The ${ }^{1} \mathrm{H} T_{2}$ relaxation data of both non-symmetrical molecules were compared to those of symmetrical tris(ureas), $\mathrm{S}_{34} \mathrm{U}_{3} \mathrm{~S}_{34}$ and $\mathrm{S}_{14} \mathrm{U}_{3} \mathrm{~S}_{14}$, which seemed reasonable even in the case of the non-symmetrical bis(urea) $\mathrm{S}_{42} \mathrm{U}_{2} \mathrm{IB}_{23}$ since the nature of the self-assembling unit, bis(urea) or tris(urea), did not significantly affect the $M(t)$ signal, see section 2.1 of the Supporting Information. The gradient of mobility along the PS arms mentioned above for the symmetrical tris(urea)s $\mathrm{S}_{34} \mathrm{U}_{3} \mathrm{~S}_{34}$ and $\mathrm{S}_{14} \mathrm{U}_{3} \mathrm{~S}_{14}$ was still present within the assemblies formed by $\mathrm{S}_{42} \mathrm{U}_{2} \mathrm{IB}_{23}$ and $\mathrm{S}_{20} \mathrm{U}_{3} \mathrm{IB}_{39}$, see Figure 4. However, the long ${ }^{1} \mathrm{H} T_{2}$ component of $M(t)$ displayed a much faster relaxation for the non-symmetrical than for the symmetrical molecules, see Figure 4. This indicated that the segmental motions of the $\mathrm{S}$ units of $\mathrm{S}_{42} \mathrm{U}_{2} \mathrm{IB}_{33}$ and $\mathrm{S}_{20} \mathrm{U}_{3} \mathrm{IB}_{39}$ far enough from the urea-based core underwent a significant slowing-down compared to the symmetrical references $\mathrm{S}_{14} \mathrm{U}_{3} \mathrm{~S}_{14}$ or $\mathrm{S}_{34} \mathrm{U}_{3} \mathrm{~S}_{34}$ (see additional details in section 2.2.3 of the Supporting Information), the effect being more pronounced for $\mathrm{S}_{20} \mathrm{U}_{3} \mathrm{IB}_{39}$ than for $\mathrm{S}_{42} \mathrm{U}_{2} \mathrm{IB}_{23}$. The origin of the slowing-down of the PS segmental mobility within the assemblies obtained with the non-symmetrical molecules compared to the situation observed for the symmetrical PS-based reference systems is still an open question. However, it is worth remarking that such a variation in the rate of the PS segmental reorientations for $\mathrm{S}_{42} \mathrm{U}_{2} \mathrm{IB}_{23}$ and $\mathrm{S}_{20} \mathrm{U}_{3} \mathrm{IB}_{39}$ could not be rationalized by a local mixing between PS and PIB arms. Indeed, in such a case, the presence of PIB arms in the vicinity of the PS chains within the supramolecular assemblies should have sped up the PS segmental motions while the opposite effect was detected. Moreover, the PIB segmental dynamics should have been correspondingly slowed-down, a feature which was not observed experimentally, as explained above. This result 
could not be explained either by a different extent of self-assembly of $\mathrm{S}_{42} \mathrm{U}_{2} \mathrm{IB}_{23}$ and $\mathrm{S}_{20} \mathrm{U}_{3} \mathrm{IB}_{39}$ since this parameter was shown not to affect the segmental mobility of the polymer units when comparing $\mathrm{IB}_{27} \mathrm{U}_{2} \mathrm{IB}_{27}$ with $\mathrm{IB}_{27} \mathrm{U}_{3} \mathrm{IB}_{27}$ or $\mathrm{S}_{14} \mathrm{U}_{3} \mathrm{~S}_{14}$ with $\mathrm{S}_{34} \mathrm{U}_{3} \mathrm{~S}_{34}$.

In summary, the 1D ${ }^{1} \mathrm{H}$ NMR transverse relaxation study of the mobility of PS and PIB arms within the self-assemblies of the non-symmetrical molecules indicated the absence of a significant mixing between PIB and PS chains at the molecular length scale.

\subsection{Spatial proximity between PS and PIB arms.}

2D ${ }^{1} \mathrm{H}$ NOESY experiments were used as a complementary NMR approach to precise the local organization of both PS and PIB arms within the supramolecular structures. This technique allows probing the spatial proximity between distinct chemical groups. More precisely, it relies on the magnetization exchange that may occur, over the mixing time $t_{\mathrm{m}}$, between two protons exhibiting a through-space dipolar interaction. In practice, the probed distances amount to a few Ångströms, typically lower than 4-5 $\AA$. In the present case, the proximity between the PS phenyl groups on one hand and the PIB methyl groups on the other hand was investigated for $\mathrm{S}_{42} \mathrm{U}_{2} \mathrm{IB}_{23}$ and $\mathrm{S}_{20} \mathrm{U}_{3} \mathrm{IB}_{39}$. Though discarded by the $1 \mathrm{D}{ }^{1} \mathrm{H}$ transverse relaxation measurements, a significant mixing of both PS and PIB arms within the self-assemblies would induce strong cross-correlation peaks between the PS aromatic $\mathrm{CH}$ protons and the $\mathrm{PIB}_{\mathrm{CH}}$ ones on the 2D NOESY spectra, as a result of their magnetization exchange occurring over $t_{\mathrm{m}}$. In contrast, the formation of cylindrical Janus particles would strongly restrict the interface between PS and PIB, so that the corresponding crosscorrelation peaks would not be detected. 


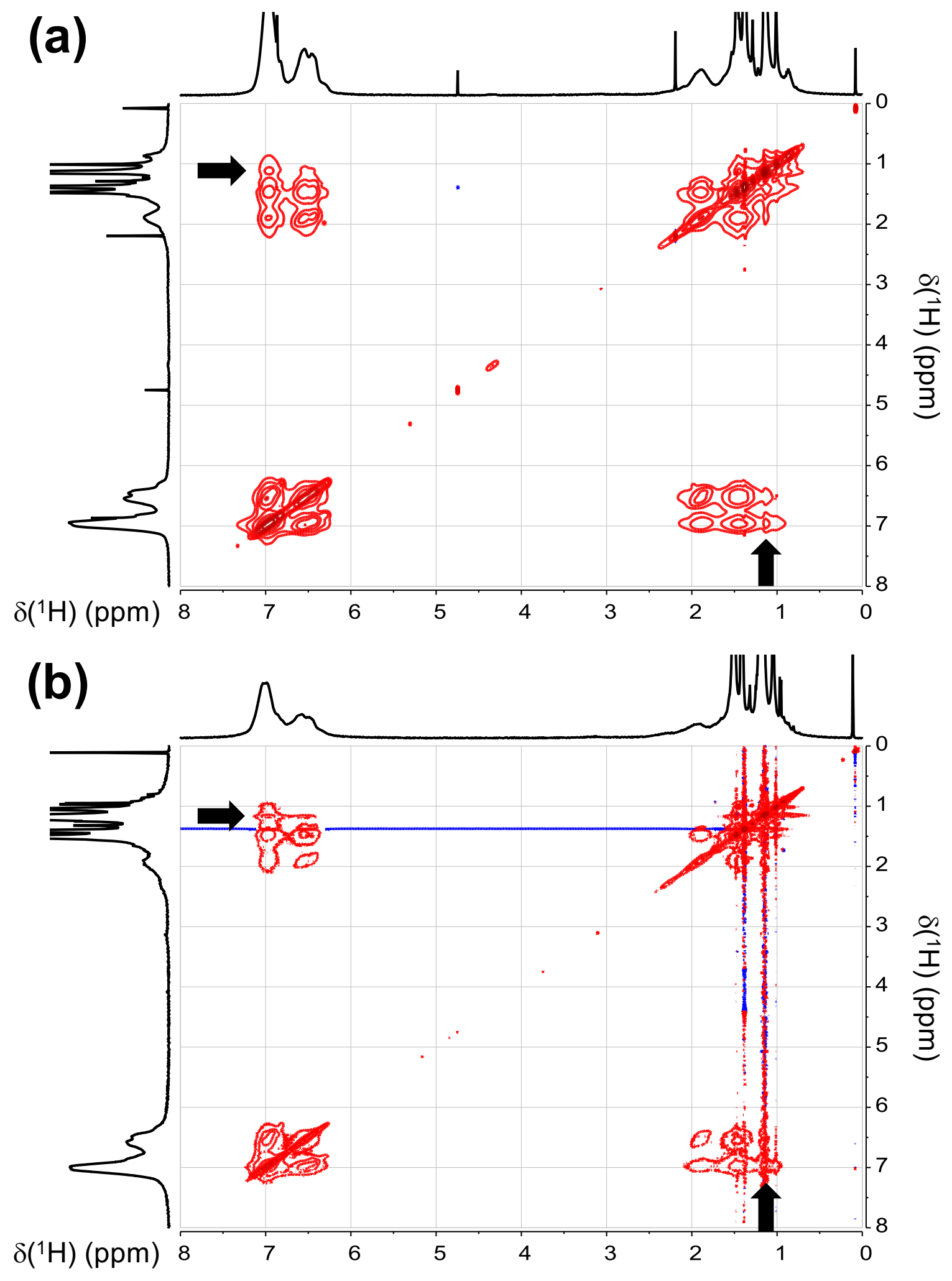


Figure 5. 2D 'H NOESY spectrum for a solution of (a) $\mathrm{S}_{42} \mathrm{U}_{2} \mathrm{IB}_{23}$ and (b) $\mathrm{S}_{20} \mathrm{U}_{3} \mathrm{IB}_{39}$ in deuterated cyclohexane. The measurements were carried out at $25^{\circ} \mathrm{C}$, with a polymer concentration of 12 g.L-1 and a mixing time $t_{\mathrm{m}}$ of $150 \mathrm{~ms}$ for (a) and $400 \mathrm{~ms}$ for (b). Cross-correlations between the protons of the phenyl groups of the PS arms and the protons of the methyl groups of the PIB arms are indicated by an arrow on a) and b).

A 2D ${ }^{1} \mathrm{H}$ NOESY spectrum obtained on $\mathrm{S}_{42} \mathrm{U}_{2} \mathrm{IB}_{23}$ in $\mathrm{C}_{6} \mathrm{D}_{12}$, at a concentration of $12 \mathrm{~g} . \mathrm{L}^{-1}$, is reported in Figure 5a. For this experiment, the mixing time was set to $150 \mathrm{~ms}$. The expected intrachain cross peaks were observed within the PS arms: among the PS aromatic protons $(\delta \approx 6.8-7.1$ ppm for the protons in the meta or para positions, $\delta \approx 6.2-6.7 \mathrm{ppm}$ for the protons in the ortho position), between both $\mathrm{CH}(\delta \approx 1.9 \mathrm{ppm})$ and $\mathrm{CH}_{2}(\delta \approx 1.4 \mathrm{ppm})$ protons of the PS backbone and between PS backbone and phenyl group protons. The cross peaks expected between the two types of PIB protons, $\mathrm{CH}_{3}(\delta \approx 1.1 \mathrm{ppm})$ and $\mathrm{CH}_{2}(\delta \approx 1.5 \mathrm{ppm})$ were detected, but with a weaker intensity. This feature may be partly rationalized by the smaller amount of PIB protons involved in $\mathrm{S}_{42} \mathrm{U}_{2} \mathrm{IB}_{23}$, compared to the PS ones, and also by their much faster $T_{1}$ relaxation. Beyond these expected cross correlations, additional cross peaks between the protons of the phenyl groups of the PS arms and the protons of the methyl groups of the PIB arms were detected, see Figure 5a. The intensity of these cross correlations was even more pronounced at a mixing time of $800 \mathrm{~ms}$. This result indicated that in the assemblies formed by $\mathrm{S}_{42} \mathrm{U}_{2} \mathrm{IB}_{23}$ in cyclohexane, a non-negligible fraction of the PS repeating units was located in the close surrounding of PIB ones.

Similar 2D ${ }^{1} \mathrm{H}$ NOESY experiments were performed on the structures induced by the nonsymmetrical tris(urea), $\mathrm{S}_{20} \mathrm{U}_{3} \mathrm{IB}_{39}$, see Figure $5 \mathrm{~b}$, corresponding to a mixing time of $400 \mathrm{~ms}$. The 
characteristic cross-correlations between the PS aromatic protons and the PIB methyl protons were also observed.

\subsection{Interpretation of the solution-state NMR experiments}

At first glance, the two sets of solution-state NMR experiments, namely ${ }^{1} \mathrm{H}$ transverse relaxation measurements and NOESY experiments, appeared contradictory. On one hand, the first approach indicated that both PIB and PS arms were mainly surrounded by arms of the same chemical nature, as would be expected for a Janus organization as depicted on Figure 6a. On the other hand, NOESY experiments indicated that at least part of the PIB arms were close $(\sim 5 \AA$ at the farthest $)$ from PS arms, which rather fitted with a mixed organization as depicted on Figure 6c.s

a)

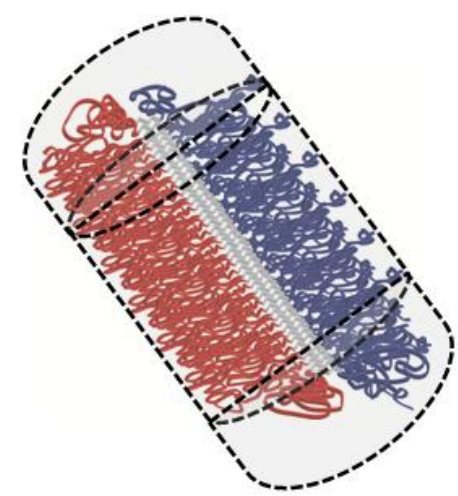

a)

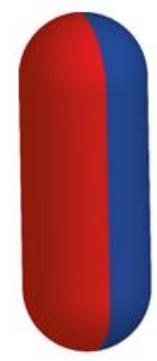

b)

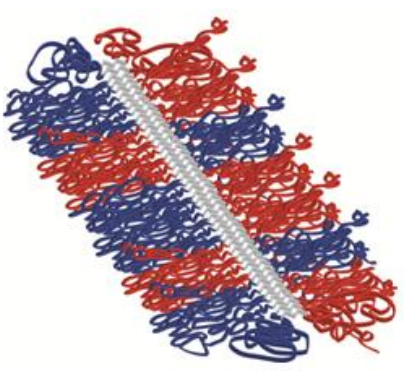

b)

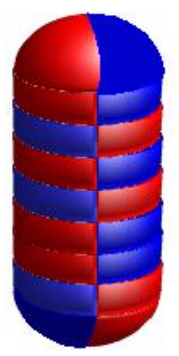

c)

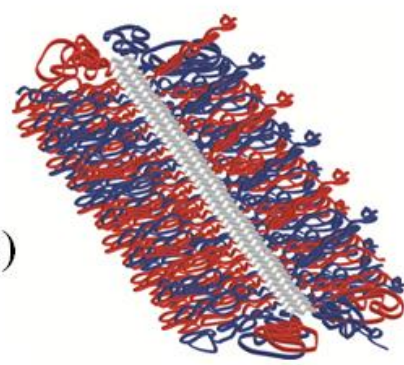

c)

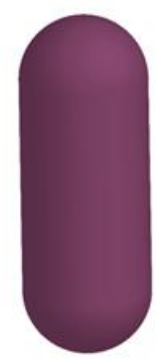

Figure 6. Possible organizations of the PS (red) and PIB (blue) arms within the self-assembled aggregates (top) and schematic view of the corresponding structures (bottom): a) perfect Janus = 
complete segregation of the PS and PIB arms, b) patchy = partial segregation of the arms, c) mixed $=$ no segregation.

Both sets of experiments could however be reconciled by considering a patchy organization (Figure 6b) where the PIB and PS arms were essentially segregated, in agreement with the $\mathrm{H}$ transverse relaxation results, but not perfectly, in agreement with the NOESY experiments. Such an incomplete phase segregation has actually been predicted by simulations ${ }^{38}$ performed on covalent bottle-brush polymers bearing two incompatible arms. Its existence could be explained by the fact that even if phase segregation is favored at short length scales, creating alternating domains of phase segregated arms by allowing a few contacts between the two types of arms is entropically very favorable and enthalpically not too demanding, especially if the arms are not strongly incompatible. Note that the fact that the two types of arms had different degrees of polymerization, which was due to technical issues (see sections 1.3 and 1.4 of the Supporting Information), may also have favoured this patchy organization. ${ }^{3.41}$

\section{Conclusion}

The self-assembly and Janus organization in cyclohexane of non-symmetrical bis(urea)s and tris(urea)s decorated by two incompatible polymer arms (PS and PIB) have been investigated by light scattering, ${ }^{1} \mathrm{H}$ transverse relaxation measurements and $2 \mathrm{D}{ }^{1} \mathrm{H}$ NOESY experiments in cyclohexane. $\mathrm{S}_{42} \mathrm{U}_{2} \mathrm{IB}_{23}$ and $\mathrm{S}_{20} \mathrm{U}_{3} \mathrm{IB}_{39}$ self-assembled by cooperative hydrogen bonding, leading to supramolecular structures. Although it is clear that the presence of a PS arm on these structures limited their self-assembly, increasing the number of hydrogen bonds from four in the bis(urea) to six in the tris(urea) allowed the formation of larger and reasonably anisotropic supramolecular 
bottle-brushes in the latter case. The ' $\mathrm{H}$ transverse relaxation measurements were shown to be a powerful solution-state NMR approach complementing the already used NOESY experiment to investigate the Janus character of polymer assemblies in solution. It should be noted that both techniques are particularly useful to study the Janus character of particles with nanometric dimensions where more classically used imaging techniques such as electron microscopy may reach their resolution limits.

It was observed that the self-assembled structures did not exhibit a perfect Janus organization in cyclohexane. Instead, the incompatibility between the PS and the PIB arms led to phase-segregated patches of the respective polymers, but was not strong enough to lead to a perfect segregation along the whole structure. Increasing the length of the polymer arms and/or choosing more strongly incompatible arms should lead to true Janus nanocylinders. Note however that the former option may limit the length and anisotropy of the self-assembled structures unless stronger hydrogen bonding units are selected. It would also be relevant to prepare molecules bearing polymer arms of similar sizes on both sides to favour a Janus organization. Although such optimized molecules have not been prepared yet, the synthetic strategy depicted in the Supporting Information could easily be adapted to obtain them, eventually leading to urea-based supramolecular Janus nanocylinders.

\section{ASSOCIATED CONTENT}

(Section 1) Synthesis of the non symmetrical bis(urea) and tris(urea). (Section 2) 'H transverse relaxation measurements of the reference symmetrical molecules $I_{27} U_{2} I B_{27}, I B_{27} U_{3} I B_{27}, S_{14} U_{3} S_{14}$ and $\mathrm{S}_{34} \mathrm{U}_{3} \mathrm{~S}_{34}$. This material is available free of charge via the Internet at http://pubs.acs.org.

\section{AUTHOR INFORMATION}




\section{Corresponding Author}

email: olivier.colombani@univ-lemans.fr

Tel: +33243833315 / Fax: +3324383 3558

\section{Author Contributions}

The manuscript was written through contributions of all authors. All authors have given approval to the final version of the manuscript.

\section{Funding Sources}

This work has been funded by the Agence Nationale de la Recherche in the frameworks ANR2011-JS08-006-01 and ANR-10-BLAN-0801.

\section{Notes}

$\S$ Note that the bis(urea) core is too large $(\sim 10 \AA)$ to expect a cross-correlation peak between protons of a PS and a PIB chain of the same molecule. No PIB/PS cross-correlations were indeed observed by NOESY for a solution of unassembled $\mathrm{S}_{42} \mathrm{U}_{2} \mathrm{IB}_{23}$ in THF. The NOESY results could thus be only accounted for by intermolecular contacts between PIB and PS arms.

One might also argue that the NOESY correlation peaks could be explained even in a perfect Janus organization (Figure 6a) by unavoidable contacts between PIB and PS arms at the ends of the aggregates or at the junctions between both sides of the cylinder. However, the number of such contacts would be too small to give NOESY correlation peaks as argued by Liu et al. ${ }^{42}$ and confirmed by Danial et al. ${ }^{17}$ for true Janus supramolecular nanocylinders.

\section{ACKNOWLEDGMENT}

The authors thank Boris Jacquette/Christophe Chassenieux, Amélie Durand, Emmanuelle Mebold and Lucie Maignan for their help respectively with the SEC, NMR, MALDI TOF MS 
analyses and discussions about Figure 6. A. Lange and BASF company are thanked for the gift of the Kerocom PIBA.

\section{REFERENCES}

1. De Gennes, P. G. Soft Matter. Science 1992, 256, 495-497.

2. Walther, A.; Müller, A. H. E. Janus Particles: Synthesis, Self-Assembly, Physical Properties, and Applications. Chem. Rev. 2013, 113, 5194-5261.

3. Walther, A.; Müller, A. H. E. Janus particles. Soft Matter 2008, 4, 663-668.

4. Perro, A.; Reculusa, S.; Ravaine, S.; Bourgeat-Lami, E.; Duguet, E. Design and synthesis of Janus micro- and nanoparticles. J. Mater. Chem. 2005, 15, 3745-3760.

5. Wurm, F.; Kilbinger, A. F. M. Polymeric Janus Particles. Angew. Chem. Int. Ed. 2009, 48, $8412-8421$.

6. $\quad$ Liu, Y.; Abetz, V.; Müller, A. H. E. Janus Cylinders. Macromolecules 2003, 36, 78947898.

7. Walther, A.; Drechsler, M.; Rosenfeldt, S.; Harnau, L.; Ballauff, M.; Abetz, V.; Müller, A. H. E. Self-Assembly of Janus Cylinders into Hierarchical Superstructures. J. Am. Chem. Soc. 2009, $131,4720-4728$.

8. Ruhland, T. M.; Gröschel, A. H.; Walther, A.; Müller, A. H. E. Janus Cylinders at LiquidLiquid Interfaces. Langmuir 2011, 27, 9807-9814.

9. Corbin, P. S.; Lawless, L. J.; Li, Z.; Ma, Y.; Witmer, M. J.; Zimmerman, S. C. Discrete and polymeric self-assembled dendrimers: Hydrogen bond-mediated assembly with high stability and high fidelity. Proc. Natl. Acad. Sci. 2002, 99, 5099-5104.

10. Park, T.; Zimmerman, S. C. A Supramolecular Multi-Block Copolymer with a High Propensity for Alternation. J. Am. Chem. Soc. 2006, 128, 13986-13987. 
11. Percec, V.; Dulcey, A. E.; Balagurusamy, V. S. K.; Miura, Y.; Smidrkal, J.; Peterca, M.; Nummelin, S.; Edlund, U.; Hudson, S. D.; Heiney, P. A.; Duan, H.; Magonov, S. N.; Vinogradov, S. A. Self-assembly of amphiphilic dendritic dipeptides into helical pores. Nature 2004, 430, $764-$ 768.

12. Scanlon, S.; Aggeli, A. Self-assembling peptide nanotubes. Nano Today 2008, 3 (3-4), 2230.

13. Pensec, S.; Nouvel, N.; Guilleman, A.; Creton, C.; Boué, F.; Bouteiller, L. Self-Assembly in Solution of a Reversible Comb-Shaped Supramolecular Polymer. Macromolecules 2010, 43, 2529-2534.

14. Catrouillet, S.; Fonteneau, C.; Bouteiller, L.; Delorme, N.; Nicol, E.; Nicolai, T.; Pensec, S.; Colombani, O. Competition Between Steric Hindrance and Hydrogen Bonding in the Formation of Supramolecular Bottle Brush Polymers. Macromolecules 2013, 46, 7911-7919.

15. Fonteneau, C.; Pensec, S.; Bouteiller, L. Versatile synthesis of reversible comb-shaped supramolecular polymers. Polym. Chem. 2014, 5 (7), 2496-2505.

16. Catrouillet, S.; Bouteiller, L.; Nicol, E.; Nicolai, T.; Pensec, S.; Jacquette, B.; Bohec, M.1. L.; Colombani, O. Self-Assembly and Critical Solubility Temperature of Supramolecular Polystyrene Bottle-Brushes in Cyclohexane. Macromolecules 2015, 48, 1364-1370.

17. Danial, M.; Tran, C. M.-N.; Young, P. G.; Perrier, S.; Jolliffe, K. A. Janus Cyclic Peptide - Polymer Nanotubes. Nat. Commun. 2013, 4, 2780.

18. Du, J.; Armes, S. P. Patchy multi-compartment micelles are formed by direct dissolution of an ABC triblock copolymer in water. Soft Matter 2010, 6 (19), 4851-4857. 
19. Voets, I. K.; Keizer, A. d.; Waard, P. d.; Frederick, P. M.; Bomans, P. H. H.; Schmalz, H.; Walter, A.; King, S. M.; Leermakers, F. A. M.; Stuart, M. A. C. Double-Faced Micelles from Water-Soluble Polymers. Angew. Chem. Int. Ed. 2006, 45 (40), 6673-6676.

20. Ghadiri, M. R.; Granja, J. R.; Milligan, R. A.; McRee, D. E.; Khazanovich, N. Selfassembling organic nanotubes based on a cyclic peptide architecture. Nature 1993, 366, 324-327.

21. Hartgerink, J. D.; Granja, J. R.; Milligan, R. A.; Ghadiri, M. R. Self-Assembling Peptide Nanotubes. J. Am. Chem. Soc. 1996, 118 (1), 43-50.

22. Huglin. Light Scattering from Polymer Solutions. Academic press: London, New York, 1972.

23. Aguilar, J. A.; Nilsson, M.; Bodenhausen, G.; Morris, G. A. Spin echo NMR spectra without J modulation. Chem. Commun. 2012, 48 (6), 811-813.

24. Carr, H. Y.; Purcell, E. M. Effects of diffusion on free precession in nuclear magnetic resonance experiments. Phys. Rev. 1954, 94 (3), 630-638.

25. Meiboom, S.; Gill, D. Modified spin-echo method for measuring nuclear relaxation times. Rev. Sci. Instrum. 1958, 29 (8), 688-691.

26. Shultz, A. R.; Flory, P. J. Phase Equilibria in Polymer-Solvent Systems. J. Am. Chem. Soc. 1952, 74 (19), 4760-4767.

27. Perez-Folch, J.; Subirana, J. A.; Aymami, J. J. Polar structure of N,N'-dimethylurea crystals. J. Chem. Crystallogr. 1997, 27, 367-369.

28. Flory, P. J. Principles of Polymer Chemistry. Cornell University Press: New York, 1953.

29. Nagata, M.; Fukuda, T.; Inagaki, H. Light scattering from polymer blend solutions. 5. Characterization of systems of relatively high incompatibility. Macromolecules 1987, 20 (9), 2173-2178. 
30. Voets, I. K.; Fokkink, R.; Hellweg, T.; King, S. M.; Waard, P. d.; Keizer, A. d.; Stuart, M.

A. C. Spontaneous symmetry breaking: formation of Janus micelles. Soft Matter 2009, 5, 9991005.

31. Voets, I. K.; Fokkink, R.; Keizer, A. d.; May, R. P.; Waard, P. d.; Stuart, M. A. C. On the Transition between a Heterogeneous and Homogeneous Corona in Mixed Polymeric Micelles. Langmuir 2008, 24, 12221-12227.

32. Voets, I. K.; Keizer, A. d.; Stuart, M. A. C.; Waard, P. d. Core and Corona Structure of Mixed Polymeric Micelles. Macromolecules 2006, 39, 5952-5955.

33. Stuart, M. A. C. Supramolecular perspectives in colloid science. Coll. Polym. Sci. 2008, $286,855-864$.

34. Pietrasik, J.; Sumerlin, B. S.; Lee, H.; Gil, R.; Matyjaszewski, K. Structural mobility of molecular bottle-brushes investigated by NMR relaxation dynamics. Polymer 2007, 48 (2), 496501.

35. Graaf, A. J. d.; Boere, K. W. M.; Kemmink, J.; Fokkink, R. G.; Nostrum, C. F. v.; Rijkers, D. T. S.; Gucht, J. v. d.; Wienk, H.; Baldus, M.; Mastrobattista, E.; Vermonden, T.; Hennink, W. E. Looped Structure of Flowerlike Micelles Revealed by 1H NMR Relaxometry and Light Scattering. Langmuir 2011, 27 (16), 9843-9848.

36. McCall, D. W.; Douglass, D. C.; Anderson, E. W. J. Nuclear magnetic relaxation in polymer melts and solutions. J. Polym. Sci. 1962,59 (168), 301-316.

37. Mirau, P. A. A Practical Guide to Understanding the NMR of Polymers. John Wiley \& Sons, Inc.: Hoboken, New Jersey, 2005.

38. Hsu, H.-P.; Paul, W.; Binder, K. Simulation of Copolymer Bottle-Brushes. Macromol. Symp. 2007, 252, 58-67. 
39. de Jong, J.; ten Brinke, G. Conformational Aspects and Intramolecular Phase Separation of Alternating Copolymacromonomers: A Computer Simulation Study. Macromol.Theory Simul. 2004, 13, 318-327.

40. Stephan, T.; Muth, S.; Schmidt, M. Shape Changes of Statistical Copolymacromonomers: From Wormlike Cylinders to Horseshoe- and Meanderlike Structures. Macromolecules 2002, 35, 9857-9860.

41. Stepanyan, R.; Subbotin, A.; ten Brinke, G. Comb Copolymer Brush with Chemically Different Side Chains. Macromolecules 2002, 35, 5640-5648.

42. Liu, X.; Yu, M.; Kim, H.; Mameli, M.; Stellacci, F. Nat. Commun. 2012, 3, 1182. 


\section{FOR TABLE OF CONTENT USE ONLY.}

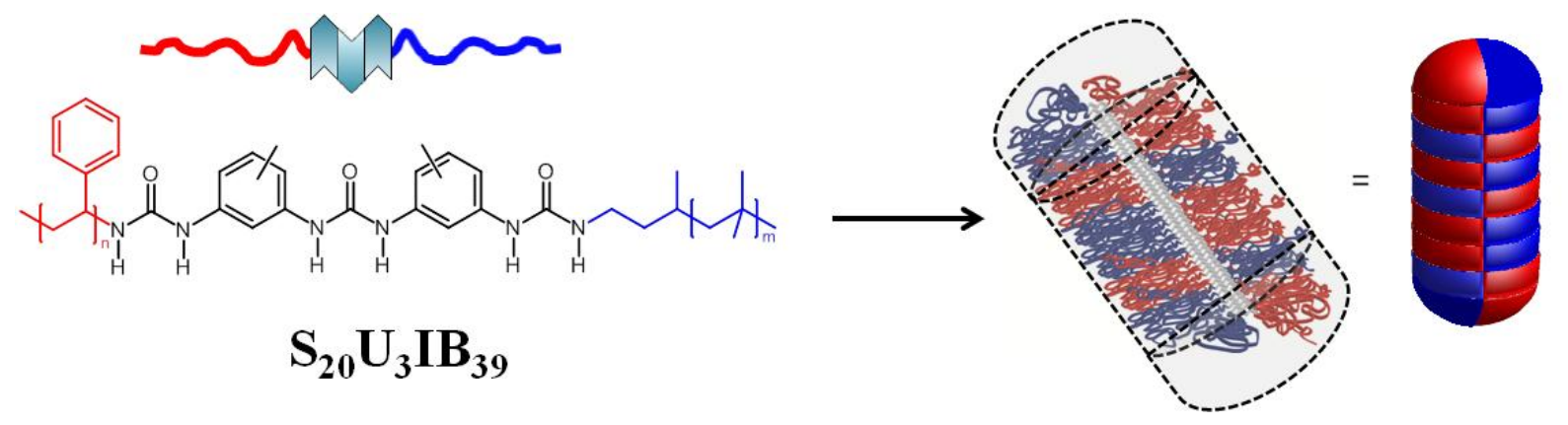

Supramolecular self-assembly in solution of a non symmetrical tris(urea) into a patchy nanocylinder by hydrogen bonding and segregation of the incompatible polymer arms. 